Veterinary Helminthology and Entomology: the Diseases of Domesticated Animals caused by Helminth and Arthropod Parasites. By Prof. H. O. Monnig. Pp. xvi+402. (London: Bailliere, Tindall and Cox, 1934.) $30 s$.

Prof. Monnig, who is professor of parasitology in the Veterinary Faculty of the University of Pretoria, is well-qualified to write a work of this character. The aim of his book is to give an account of the helminth and arthropod parasites of domestic animals and, at the same time, to stress those practical aspects of the subject most useful to the veterinarian. The morphology of the parasites concerned is dealt with in a general way and sufficient account is given about their general characteristics to enable specific parasites to be identified. The parasitic diseases themselves and their treatment come in for rather fuller consideration. The chief parasites of the common domestic animals of the world, and also kindred creatures affecting fur-bearing mammals, are included. If important parasites have been omitted it is only because, the author states, discrimination on this subject is difficult on the basis of existing knowledge.

The book is divided into four parts or sections, of which Sections I and II are brief (they occupy together less than 22 pages) and are mainly introductory. Section I is concerned with the general subject of parasitism, resistance and immunity, pathogenicity and kindred topics. In Section II methods of preserving and mounting material are described, but the part is devoted more especially to clinical methods of diagnosing parasitic diseases. The longest part of the book is Section III, on helminth parasites (more than 230 pages), while Section IV, on arthropod parasites, occupies about 133 pages. The author evidently favours the helminths more than the arthropods, and their treatment is often more detailed, apart from the fact that they include the larger number of species of veterinary importance.

The subject matter of the book is well arranged and thoroughly up to date, while the illustrations are admirably clear and well executed and the majority of the figures are new and original. The book will undoubtedly well serve the purpose intended, and should meet the requirements of both the student and practising veterinarian. It should also be on the shelves of zoological libraries.

Qualitative Analyse mit hilfe von Tüpfelreaktionen: theoretische Grundlagen, praktische Ausfuhrung und Anwendung. Von Dr. Fritz Feigl. Zweite, verbesserte und vermehrte Auflage. Pp. xii $+\mathbf{5 1 3}$. (Leipzig: Akademische Verlagsgesellschaft m.b.H., 1935.) 28 gold marks.

IT is gratifying to note that the second edition of this invaluable guide to 'spot' tests has been published within four years of the first edition (reviewed in NATURE of December 12, 1931), and that it has not been necessary to raise its price, in spite of the fact that it has been enlarged and partly rewritten. Actually, the number of pages has been increased by more than thirty per cent, much of the increase being necessary to include work, published and unpublished, carried out in the author's own laboratory.

Besides covering in the most detailed manner every variety of spot test for inorganic and for organic substances, the book contains 116 pages of theoretical discussion, under which head are considered complex-formation, co-ordination of elements, poly-acids, catalysed and induced reactions, the various groups 'specific' to particular metals and so on. Many of the tests appear twice in the book, according to whether $A$ is used as specific for $B$, or $B$ as specific for $A$. At the end of the book is found a tabular summary covering ten pages, an author index covering nine, and a subject index covering nearly nineteen. The utility of the book should secure for it a wide public, quite apart from its inevitable appearance on the book-shelves of every micro-chemist.

A. L. B.

War Office. Textbook of Mechanical Engineering Pp. xv $+690+x x$. (London : H.M. Stationery Office, 1934.) 12s. net.

TwIs is the best twelve shillings' worth of information on mechanical engineering we have ever come across, and it is scarcely possible to conceive a better guide for the young engineer. In it theory and practice are combined in an admirable manner, and it is full of those 'wrinkles' which only the experienced engineer can impart. It covers workshop practice, all the ordinary types of reciprocating steam, petrol and oil engines, boilers, power transmission, lubrication, air compressors and refrigeration. There are diagrams, tables, charts, bibliographies and a good index, and the information is conveyed with an economy of language which sometimes reminds one of the drill shed. The production of the book it may be presumed is the result of team work, but it is quite evident that a good deal of credit is due to the editor, whoever he may be. $\quad$ E. C. S.

\section{A Guide to the Constellations}

By Prof. Samuel G. Barton and Prof. Wm. H. Barton, Jr. (McGraw-Hill Astronomical Series.) (Whittlesey House Publication.) Second edition. Pp. $x+74$. (New York and London : McGraw-Hill Book Co., Inc., 1935.) 15s, net.

The first edition of this atlas was noticed in NaTURE of November 10, 1928 (p. 723). In the new edition the authors have made slight alterations to the text, necessitated by recent developments such as the discovery of Pluto. The charts themselves appear to be unaltered, and the opportunity has not been taken of introducing the new constellation boundaries as defined by the International Astronomical Union. This, however, is of minor importance to the class of readers for whom the book is intended, and who will find it not only an excellent help in becoming familiar with the constellations but also a trustworthy source of elementary astronomical information. 